\title{
Estudo retrospectivo de exames citológicos realizados em um Hospital Veterinário Escola em um período de cinco anos
}

\author{
[Retrospective study on the cytological exams in a Veterinary Technic Hospital in a five year period] \\ M.C. Rosolem ${ }^{1}$, L.R. Moroz ${ }^{2}$, S.M. Rodigheri ${ }^{1}$, U.J. Corrêa Neto ${ }^{3}$, \\ C.D. Porto ${ }^{4}$, J.S. Hanel ${ }^{4}$ \\ ${ }^{1}$ Faculdade de Ciências Agrárias e Veterinárias - FCAV-Unesp- Jaboticabal, SP \\ ${ }^{2}$ Faculdade de Medicina Veterinária e Zootecnia - FMVZ-USP-São Paulo, SP \\ ${ }^{3}$ Universidade Estadual de Maringá - Maringá, PR \\ ${ }^{4}$ Faculdade Integrado de Campo Mourão - Campo Mourão, PR
}

\begin{abstract}
RESUMO
Avaliaram-se os resultados de exames citológicos realizados em seis anos e determinou-se o tipo de distúrbio (inflamatório, infeccioso, proliferativo) mais comum. Aspectos epidemiológicos, como espécie, raça, sexo e idade, foram levados em consideração. Foram realizadas 270 avaliações citológicas e destas a prevalência foi de neoplasmas (53\%). A espécie canina foi a mais ocorrente, com $92 \%$ dos casos. As fêmeas somaram 53\% do total. A idade variou de um a 17 anos, sendo o intervalo de seis a 10 anos mais ocorrente (40\% dos casos). As neoplasias de células redondas foram as mais prevalentes, seguidas das neoformações mamárias.
\end{abstract}

Palavras-chaves: pequenos animais domésticos, citologia aspirativa, neoplasma

\begin{abstract}
The cytological exam is a practical diagnostic aplication which allows the detection of inflammatory, proliferative and infectious disturbances. In the present study, the results of cytological exams during six years were evaluated, determining the most common type of disorder (inflammatory, infectious, proliferative). Epidemiological aspects such as species, breed, sex and age were taken into account. 270 reviews were evaluated and the prevalence was neoplasms (53\%). The canine specie was the most observed, with $92 \%$ of cases. Females totaled $53 \%$. The age ranged from one to 17 years and the interval of six to 10 years was most observed (40\% of cases). The round cell neoplasms were the most prevalent, followed by breast neoformations.
\end{abstract}

Keywords: domestic small animals, aspiration cytology, neoplasm

\section{INTRODUÇÃO}

O método diagnóstico baseado na análise citológica consiste na avaliação individualizada de células. Foi introduzido na rotina veterinária brasileira apenas a partir da década de 90 , com o intuito de propiciar rapidez nas avaliações clínicas ambulatoriais. Esse exame é capaz de fornecer a origem celular e, consequentemente, o diagnóstico de diversas tumorações, sejam elas de origem cancerosa, inflamatória, hiperplásica ou ainda infecciosa. A citologia auxilia no estabelecimento do prognóstico, na identificação de metástases e no monitoramento da evolução/involução de neoplasias (Guedes et al., 2000; Rosseto et al., 2008). Historicamente, há divergências sobre o real início do uso do exame citológico na medicina; sabe-se que ocorreram nos primórdios do século XX, primeiramente empregado no estudo de doenças infecciosas e, posteriormente, no estudo de neoplasias (Schimitt, 1997; Santos, 2010).

Recebido em 6 de novembro de 2011

Aceito em 26 de novembro de 2012

E-mail: mayara_rosolem@yahoo.com.br 
Existem várias técnicas de biópsias disponíveis para a obtenção de amostras de um tecido ou apenas de um grupo celular. As mais comuns são a biópsia incisional, que retira apenas um ou vários pequenos fragmentos de um tecido. A biópsia excisional retira todo tecido lesado, com margem de segurança ampla, sempre que possível. A biópsia por aspiração, também conhecida como citologia aspirativa por agulha fina (CAAF), consiste na avaliação punção de glândulas, linfonodos e formações nodulares. A biópsia esfoliativa é indicada para lesões externas. O material é obtido com o auxílio de uma lâmina de bisturi ou, até mesmo, uma lâmina de vidro (muito utilizada para casos de dermatoses). A biópsia por imprinting é utilizada para a remoção de células superficiais por meio do simples contato da superfície da lesão com a superfície de uma lâmina de microscopia, funcionando com um "adesivo". A biópsia por swab também se dá por contato e é geralmente usada quando outros métodos não são práticos para determinada situação, como na mucosa vaginal ou da orelha externa (Cowell et al, 2008a; Stewens e Lowe, 2002).

Na CAAF, que é uma das formas de biópsia mais utilizadas atualmente, o material aspirado é depositado em lâmina de vidro e dele faz-se um esfregaço para, então, ser corado e observado em microscopia óptica. As fronteiras diagnósticas ampliam-se significativamente quando a interpretação morfológica é combinada com outros exames, como os por imagem, laboratoriais e a análise histopatológica (Schimitt, 1997). Essa técnica disponibiliza células ou um grupo destas e não possibilita a verificação da total arquitetura tecidual (Banks, 1991). Para isso, deve-se complementar com a análise histológica (pela obtenção de material por biopsia incisional ou excisional), que definirá o diagnóstico final.

As principais vantagens da CAAF incluem o preço acessível, a fácil obtenção do material, a mínima sedação (ou mesmo nenhuma) e a menor escala invasiva (Kristensen et al., 1990). Entre as desvantagens, estão a pequena quantia de material que é adquirido e ainda a possível lise das células durante a preparação do esfregaço, diminuindo a qualidade delas e prejudicando a qualidade da leitura (Morrison e de Nicola, 1993). Wellman (1996) citado por Magalhães et al. (2001) observa que hemorragia, infecção, injúria ao tecido adjacente e disseminação de células neoplásicas podem acontecer no momento da punção, porém são raras.

A análise histopatológica permite a inspeção das margens cirúrgicas e a verificação dos tecidos adjacentes, que incluem linfonodos, vasos sanguíneos e linfáticos. É uma avaliação superior à citológica por conseguir acessar a estrutura e a arquitetura dos tecidos relacionados ao tecido acometido. Além disso, fornece precisão e pode ser comparada depois ao resultado citopatológico. Sua desvantagem está no custo e no tempo de preparação e de análise. Há ainda a necessidade de sedação do paciente, pois essa forma diagnóstica requer maior quantidade de tecido organizado, sendo mais invasiva que a citológica (Morrison e De Nicola, 1993). Portanto, a citologia, apesar de rápida e pouco invasiva, não possui a mesma acurácia diagnóstica do exame histopatológico.

O exame citopatológico foi e ainda é muito associado ao diagnóstico exclusivo de neoplasias; no entanto, é passível de encontrar tecido sem quaisquer relações com neoplasmas, tais como: hiperplasia, cistos, infiltrado inflamatório, de conteúdo infeccioso, material não diagnóstico (Raskin e Meyer, 2003).

Ao abordar processos neoplásicos é importante observar e quantificar a presença dos critérios de malignidade celulares presentes no núcleo, nucléolo e citoplasma (Tab. 1). Células de tecido normal, tecido hiperplásico e tumorações benignas geralmente não apresentam tais alterações morfológicas em número suficiente. Para classificar uma lesão como processo neoplásico maligno, é necessário observar alterações tanto em núcleo como em citoplasma, sendo necessárias pelo menos três alterações nucleares e cinco citoplasmáticas. Alguns critérios de malignidade possuem maior peso, especialmente os de origem nuclear. A presença de nucléolos angulares, mitoses bizarras e moldagem nuclear constitui alterações altamente sugestivas de malignidade (Raskin e Meyer, 2003; Cowell et al., 2008b). 
Tabela 1. Critérios de malignidade celular

\begin{tabular}{lcc}
\hline \multicolumn{1}{c}{ Critérios gerais } & Critérios citoplasmáticos & Critério nucleares \\
\hline Anisocitose & Aderências & Relação núcleo/citoplasma \\
Pleomorfismo & Distinção & Anisocariose \\
Heterotopia & Vacúolos & Multinucleação \\
Emperipolese & & Número de figuras mitóticas \\
Hipercelularidade & & Padrão cromatínico \\
Homogeneidade morfológica & Nucléolos visíveis \\
Macrocitose & & Mitoses atípicas \\
\hline
\end{tabular}

Fonte: Cowell, et al. (2008 b); Stewens (2002).

As células malignas são morfologicamente diferenciadas da população celular progenitora. Com base nas características citológicas predominantes, a malignidade pode ser classificada como carcinoma (se a origem for epitelial) ou sarcoma (origem mesenquimal). Se as células neoplásicas forem originárias do tecido hematopoiético, recebem a denominação de tumor de células redondas (Nelson e Couto, 2001), apesar de fazerem parte de tecido mesenquimal. Isso justifica por que em algumas literaturas o linfoma é chamado de linfossarcoma. Uma exceção é o tumor venéreo transmissível (TVT), que é enquadrado como célula redonda, entretanto não possui origem hematopoiética. O melanoma é outro tumor cuja classificação em tipo celular ainda gera controvérsias, pois possui morfologia redonda, Alguns autores, todavia, classificam-no como célula mesenquimal, já que sua origem é da neuroepiderme e ele se encontra no tecido conjuntivo (Raskin e Meyer, 2003; Cowell et al., 2008b).

Neoplasmas de origem glandular podem gerar amostras em que são observados núcleos livres, como, por exemplo, os adenocarcinomas ovarianos, tireoideos e paratireoideos. Alguns autores os classificam como tumores de células epiteliais glandulares; outros, como tumores de origem livre (Raskin e Meyer, 2003; Cowell et al., 2008b).

Os objetivos deste estudo retrospectivo foram determinar os diagnósticos citopatológicos de distúrbios proliferativos, dividindo sua origem em neoplásica e não neoplásica e determinar qual o tipo celular prevalente nos processos neoplásicos por meio do exame citopatológico.

\section{MATERIAIS E MÉTODOS}

O estudo abrangeu o período de cinco anos, de março de 2006 a março de 2011, em que foram realizados 270 exames citológicos de 230 pacientes, oriundos do atendimento do Laboratório de Anatomia Patológica pertencente a um Hospital Veterinário Escola, localizado em Campo Mourão, na região noroeste do Paraná. As colorações utilizadas para análise citológica foram, preferencialmente, a de Giemsa e, menos comumente, a de Diff-Quik, também conhecida como panótico rápido.

Os resultados foram divididos nos seguintes grupos: inflamatórios - piogranulomatoso, granulomatoso e infiltrado neutrofílico; tumorais - benigno ou maligno; material impróprio para análise, tecido normal e alterações diversas. Ainda, foram avaliadas as variáveis: espécie, raça e idade.

\section{RESULTADOS E DISCUSSÃO}

Foram realizadas 270 citologias, sendo a espécie canina a mais prevalente $(92 \%)$, seguida da felina $(4 \%)$, equina $(2 \%)$ e outros $(2 \%)$ - três camundongos e um papagaio verdadeiro.

Cento e quarenta análises $(53 \%)$ resultaram em alguma forma neoplásica, $55 \quad(20 \%) \mathrm{em}$ processos inflamatórios, $23(7 \%)$ em material impróprio para análise ou resultado inconclusivo, $10(5 \%)$ indicaram células normais (ausência de alterações de neoplásicas ou de reações inflamatórias), e os 40 restantes (15\%) são referentes a outras alterações detectadas, que incluem cistos epidermoides, hiperplasias prostáticas benignas, calcificações, sialoceles (Fig. 1). Os resultados obtidos demonstraram a alta incidência de neoplasias nos anos estudados. As neoplasias representaram, no ano de 2006, $46 \%$ dos casos. Em 2007, chegaram a 49\%, em 2008 foram $57 \%$, em 2009 totalizaram $62 \%$, em $2010,70 \%$ e em $2011,60 \%$. 


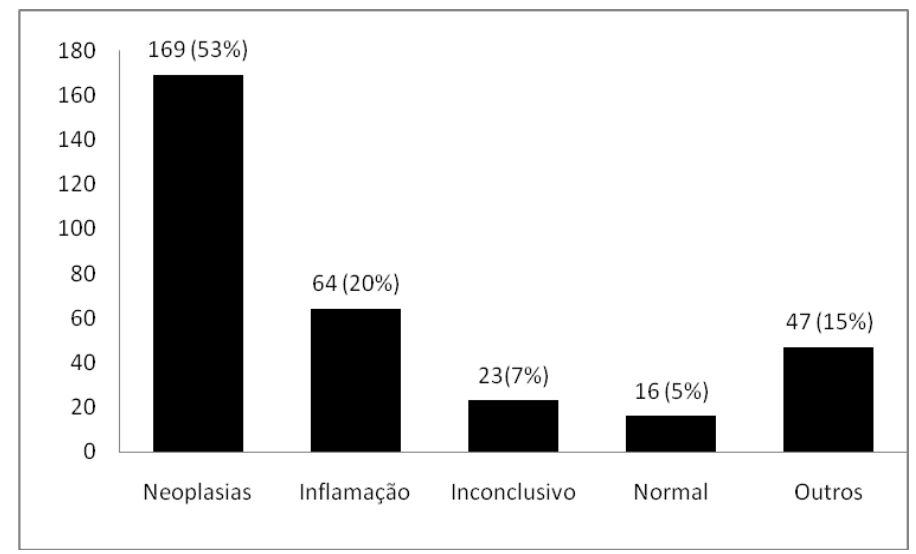

Figura 1. Resultados gerais encontrados nas citologias aspirativas por agulha fina no período de março de 2006 a março de 2011.

Entre as amostras que resultaram em neoplasmas, a origem celular mais encontrada foi a de células redondas com 69 amostras (49\%), seguidas dos tumores de células epiteliais, com 47 amostras (34\%). Apenas 24 das citologias $(17 \%)$ apresentaram características de tumores de células mesenquimais.

Muitos estudos trazem os tumores de origem epitelial como sendo os mais frequentes, como o que é descrito no estudo de Amaral (2004), principalmente os mamários. Ao avaliar os dados gerais, este estudo difere dos resultados do autor citado. Pode-se supor que a grande incidência de cães errantes na região possa ser uma das causas dessa inversão de tipo celular prevalente, uma vez que o principal tumor de célula redonda diagnosticado foi o TVT, segundo mostra a Fig. 2.

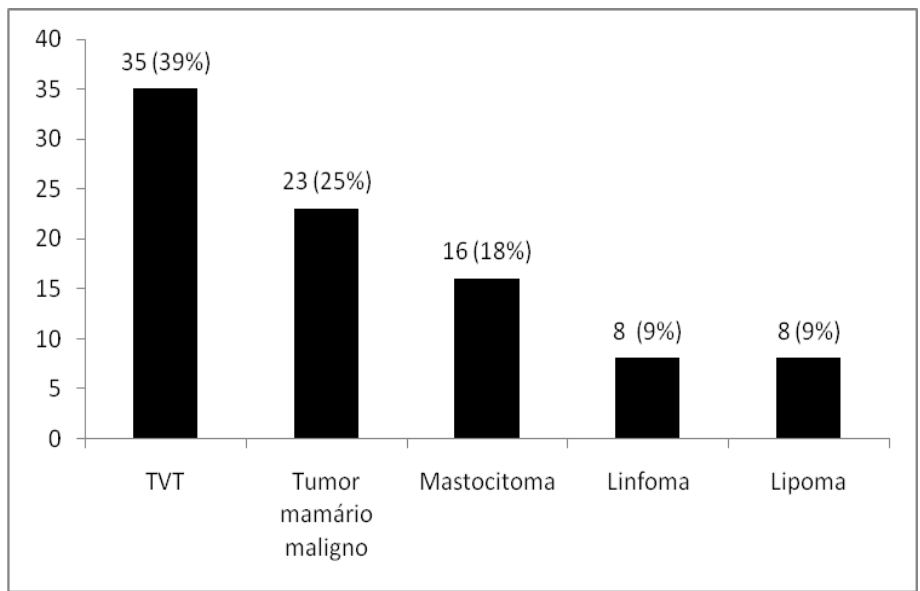

Figura 2. Neoplasias e tumores mais diagnosticados.

Esse levantamento se assemelha ao de Nelson e Couto (2001), ao revelarem que os tumores mamários constituem a segunda forma mais comum de neoplasia em cães, sendo superados apenas pelos tumores de pele. Deve-se levar em consideração que os tipos neoplásicos mais ocorrentes na derme foram pouco encontrados na região de Campo Mourão, em especial o carcinoma de células escamosas.
Quanto aos processos inflamatórios, observaramse 55 (20\%), classificados como: processos inflamatórios neutrofílicos (PIN), processos inflamatórios piogranulomatosos (PIPG) e processos inflamatórios granulomatosos (PIG). Os dados estão apresentados na Fig. 3. 


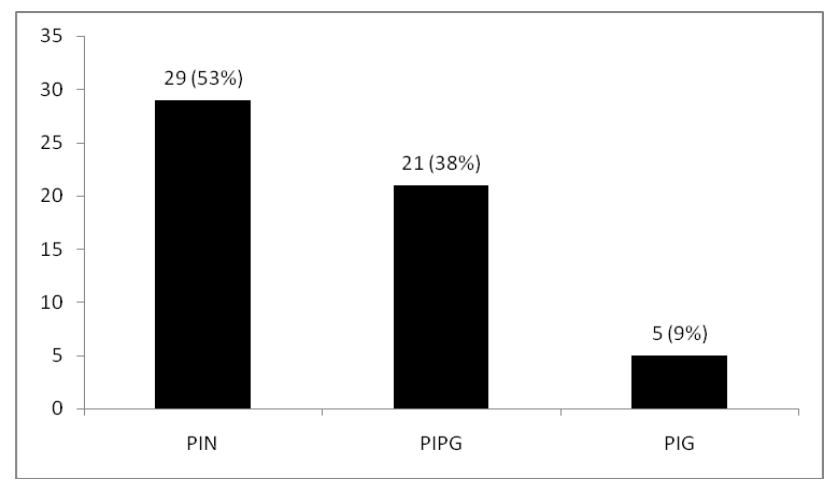

Figura 3. Distribuição dos processos inflamatórios. (PIN: processo inflamatório neutrofílico; PIPG: processo inflamatório piogranulomatoso; PIG: processo inflamatório granulomatoso).

O tipo de infiltrado inflamatório é de grande importância para o diagnóstico diferencial. Sua classificação é dada como processo inflamatório neutrofílico quando mais de $85 \%$ do infiltrado inflamatório apresentar neutrófilos; processo inflamatório granulomatoso, maior porcentagem de macrófagos; processo inflamatório piogranulomatosos, presença de macrófagos e neutrófilos na proporção próxima (Tostes e Bandarra, 2000; Raskin e Meyer, 2003).

Dos nove gatos avaliados, observaram-se três tumores malignos de glândula mamária, um tumor benigno de glândula mamária e um tumor de células redondas (linfoma). Apesar de estes dados contradizerem os estudos em veterinária que afirmam que as neoplasias mamárias constituem o terceiro tipo mais comum, seguidas dos tumores de pele e dos tumores do sistema hemolinfático (Nelson e Couto, 2001), o baixo número de avaliados impede uma conclusão adequada, sendo necessários maiores estudos na espécie felina. Entre as raças felinas estão quatro Siameses, três sem raça definida (SRD), um Persa e um Russian Blue.

Entre as raças caninas mais acometidas estão os animais sem raça definida (SRD), com 88 animais, 16 Boxers, 12 Cockers, 10 Pinschers, nove Poodles e sete Pit Bulls (Fig. 4). Apesar de estas raças serem comuns na região, o que poderia se tornar um viés, observa-se que outras raças comuns, tais como Rottweiler, Teckel, Labrador, Akita e Dogue Alemão tiveram poucos casos de diagnóstico neoplásico por análise citopatológica. Isto pode ser um indício de que raças como Boxer e Cocker podem apresentar susceptibilidade ao câncer, contudo mais estudos são necessários para conclusões significativas.

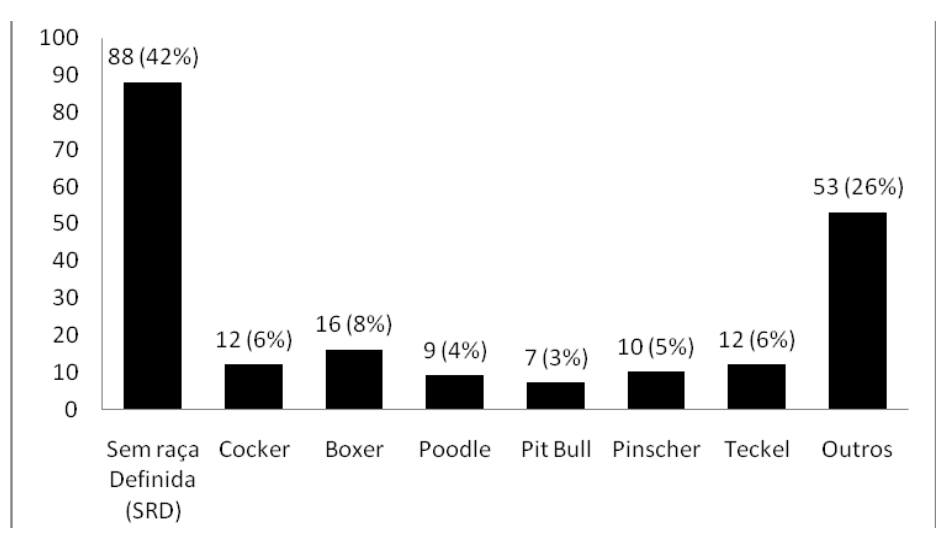

Figura 4. Distribuição das raças caninas prevalentes nas avaliações citológicas, no período de março de 2006 a março de 2011. Os 26\% restantes, classificados como "outros", estão cinco Basset Hounds, cinco Pastores Alemães, quatro Rotwelleirs, três Huskys Siberianos, três Labradores, dois Bassets, um Pointer, um Malamute, um Fox Paulistinha, um Lhasa Apso, um Akita, um Dálmata, um Pequinês, um Yorkshire e um Dogue Alemão, além de 16 animais que não tiveram sua raça informada. 
Dos 230 pacientes estudados, as fêmeas foram as mais ocorrentes, representando 122 casos (53\%), não havendo diferença significativa entre sexo, semelhante a Cardoso (2003), que afirmou que os cães não apresentam predisposição sexual para desenvolverem neoplasias.

A idade dos animais estudados variou de três meses a 17 anos. Essa amplitude de idade é justificada pelo fato de que a citologia foi realizada não apenas com o intuito de diagnóstico tumoral, mas também como diagnóstico de processos inflamatórios. Quanto ao diagnóstico tumoral, a idade mais frequente está entre seis e 10 anos, o que condiz com Gomes (2006), que citou o quão as neoplasias são mais comuns em animais de meia-idade a geriátricos (Fig. 5).

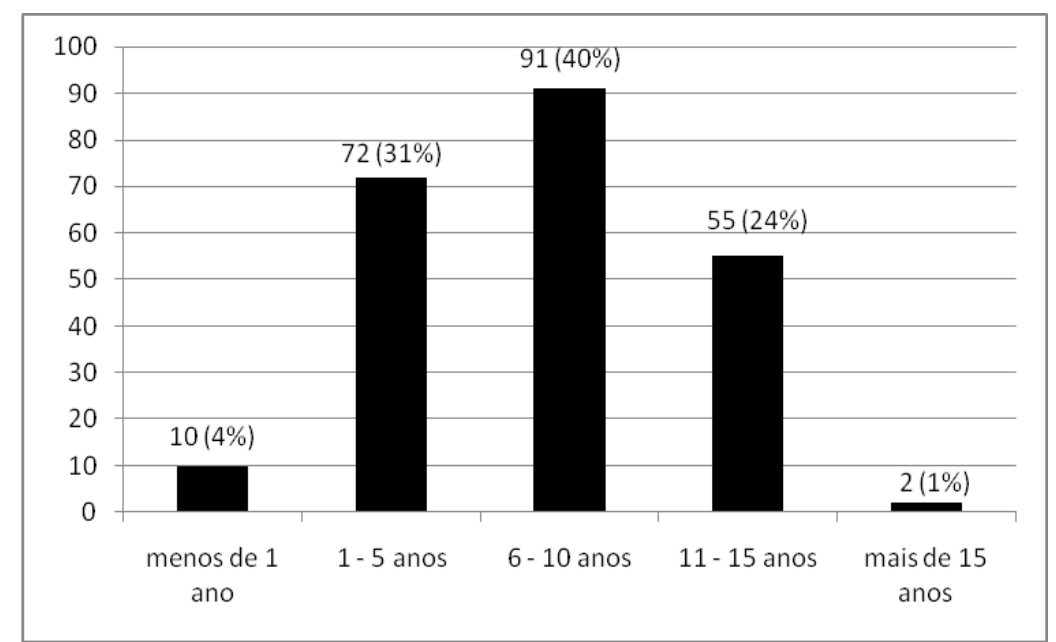

Figura 5. Frequência das idades mais acometidas por alterações neoplásicas e requisitadas para exame citológico, no período de março de 2006 a março de 2011.

Entre os exames que revelaram material impróprio para análise, inconclusivo e outros, somam-se 63 resultados (22\%). Estes podem ser justificados, pois tumores de origem mesenquimal, sólidos e complexos e mistos, possuem baixa capacidade esfoliativa, e processos císticos podem conter poucas células, inviabilizando a análise citopatológica adequada (Allen, 1986).

\section{CONCLUSÕES}

Os neoplasmas foram o diagnóstico mais encontrado, e o tipo tumoral mais observado foi o tumor de células redondas, explicado pelo grande número de casos de TVT, que é um tumor de fácil esfoliação. As citologias de fêmeas prevaleceram e a idade mais acometida pelas neoplasias ficou entre seis e 10 anos. O exame citopatológico é uma ótima opção para diagnóstico rápido e complementar de processos neoplásicos, inflamatórios, infecciosos, entre outros. Apesar de sua baixa especificidade por não avaliar arquitetura do tecido, seus resultados guiam o clínico quanto à expectativa de margem de segurança e possíveis tratamentos. Sua simplicidade e rapidez não dispensam a realização do exame histológico, e se os métodos forem aliados, mostrarão interpretações mais fundamentadas, aumentando a acurácia diagnóstica e permitindo tratamento específico.

\section{REFERÊNCIAS}

ALLEN, S.W.; PRASSE, K.W.; MAHAFFEY, E.A. Cytologic differentiation of benign from malignant canine mammary tumors. Vet. Pathol., v.23, p.649-655, 1986.

AMARAL, A.S.; GASPAR, L.F.J.; SILVA, S.B.; ROCHA, N.S. Diagnóstico Citológico do Tumor Venéreo Transmissível na Região de Botucatu, Brasil (Estudo Descritivo: 1994-2003). $R P C V$, v.99, p.167-171, 2004.

BANKS, W.J. Introdução à Citologia Esfoliativa. In:_. Histologia Veterinária Aplicada. São Paulo: Manole, 2.ed., cap.29, 1991. p.620-629. 
CARDOSO, M.J.L.; MACHADO, L.H.A.; ROCHA, N.S. et al. Linfoma canino: Revisão de cinquenta e quatro casos. Biosci. J., v.19, p.131142, 2003.

COWELL R. L; TYLER R.D; MEINKOTH, J.H; DE NICOLA, D. B. Sample Collection and Preparation. In:_.Diagnosis Cytology and Hematology of the Dog and Cat. St. Louis: Mosby, ed 3th, chapter 1. p.1-19, 2008 a.

COWELL R.L; TYLER R.D; MEINKOTH, J.H; DE NICOLA, D. B. Cell Types and Criteria of Malignancy. In:_.Diagnosis Cytology and Hematology of the Dog and Cat. St. Louis: Mosby, ed 3th, chapter 2. p.20-46, 2008 b.

GOMES, C.; FERREIRA, M.P.; ERREIRA, K.C.R.S. et al. Estudo epidemiológico de cães com imagens radiográficas compatíveis com neoplasias ósseas. Acta Sci. Vet., v.34, p.159$162,2006$.

GUEDES, R.M.C.; ZICA, K.G.B.; COELHOGUEDES, M.I.M.; OLIVEIRA, S.R. Acurácia do exame citológico no diagnóstico de processos inflamatórios e proliferativos dos animais domésticos. Arq. Bras. Med. Vet. Zootec., v.52, p.437-439, 2000.

KRISTENSEN, A.T.; WEISS, D.J.; KLAUSNER, J.S.; HARDY, R.M. Liver cytology in cases of canine and feline hepatic disease. Comp. of Cont. Educ. for the Pract. Vet., v.12, p.797-808, 1990.

MAGALHÃES, A.M.; RAMADINHA, R.R.; BARROS, C.S.L.; PEIXOTO, P.V. Estudo comparativo entre citopatologia e histopatologia no diagnóstico de neoplasias caninas. Pesq. Vet. Bras., v.21, p.23-32, 2001.
MORRISON, W.B, DeNICOLA, D.B. Advantages and disadvantages of cytology and histopathology for the diagnosis of cancer. Sem. in Vet. Med. \& Surgery (Small Animal), v.8, p.222-227, 1993.

NELSON, R.W; COUTO, C.G. Medicina Interna de Pequenos Animais. 2.ed. Rio de Janeiro: Guanabara e Koogan, 2001, p. 1084.

RASKIN, R.E; MEYER, D.J. Atlas de Citologia de Cães e Gatos. 1.ed. São Paulo: Roca, 2003. $354 \mathrm{p}$.

ROSSETTO, V.J.V.; MORENO, K.; GROTTI, C.B. et al. Frequência de neoplasmas em cães diagnosticados por exame citológico: estudo retrospectivo em um hospital-escola. Semina: Cienc. Agrárias, v.30, p.189-200, 2009.

SANTOS, A.P.C. Análise comparativa da punção aspirativa por agulha fina (paaf) em relação a biópsia em cavidade oral e região de cabeça e pescoço. 2010. 67f. Dissertação (Mestrado em Odontologia) - Faculdade de Odontologia, Universidade de São Paulo, SP.

SCHIMITT, F.C. Citologia aspirativa em doenças infecciosas. Rev. Soc. Bras. Med. Trop., v.30, p.177-179, 1997.

STEWENS, A; LOWE, J. Neoplasias. In: Patologia. 2.ed, Barueri:Manole, 2002, cap.6. p.103-104. 